\title{
THE IMPACT OF HUMAN RESOURCE MANAGEMENT ON THE ACTIVITIES OF NON-GOVERNMENTAL ORGANIZATIONS USING STATISTICAL APPROACHES
}

\author{
Alexander Vasyaev ${ }^{1 *}$, Yulia Ryzhova ${ }^{2}$, Nadiya Stovolos ${ }^{3}$, Lyudmila Belova ${ }^{4}$ \\ ${ }^{1 *}$ Kutafin Moscow State Law University (MSAL), Moscow, Russian Federation; ${ }^{2}$ State University of Management, \\ Moscow, Russian Federation; ${ }^{3}$ Sumy National Agrarian University, Sumy, Ukraine; ${ }^{4}$ South-Ural State University, \\ Chelyabinsk, Russian Federation. \\ Email: "alex.vasyaev@ rambler.ru
}

Article History: Received on $23^{\text {rd }}$ December 2019, Revised on $14^{\text {th }}$ April 2020, Published on $26^{\text {th }}$ May 2020

\begin{abstract}
Purpose of the study: The purpose of the study is to detect and track the possible correlation between the activities of non-governmental organizations and human resource management. This study also goal to investigate the role of the manager in fulfilling the prerequisites to reach the prosperity and flourishment within a group that works on a certain end.

Methodology: To achieve the objectives of the study, a survey of the management and employees of six nongovernmental organizations operating in various fields (educational, sports, charitable, scientific) was conducted. A total of 150 people were interviewed. The Pearson chi-squared test was used to calculate preliminary approaches that are recently using and final findings.

Main Findings: The pilot analysis using the Pearson chi-squared method revealed that the personnel policy can have a positive effect on the organization, as it allows hiring qualified employees and promotes employee motivation. According to Pearson's chi-square criterion, it was found out that there is no statistically important relationship between human resource management and the operation of non-governmental organizations.

Applications of this study: This may be explained by the fact that there are other significant factors affecting the operation of the company and being involved in the human resource management policy. However, a competent personnel policy is one of the components of the successful development of the company.

Novelty/Originality of this study: The originality of this study is that this revealed that organizations should have clear requirements for their employees in order to hire them in accordance with the company criteria. In addition, it is necessary to create a favorable working environment, as well as to consider human resource management when setting the development priorities of the organization.
\end{abstract}

Keywords: Human Resource Practices, Job Satisfaction, Organizational Performance, Human Resource Management, Non-governmental Organizations.

\section{INTRODUCTION}

The strategic human resource management and its correlation with strategic goals and objectives for increasing business efficiency and developing an organizational culture that promotes innovation and flexibility are important issues in a competitive market economy. Is the act of pulling in, creating, fulfilling, and holding representatives to serve both the workers as people and the association all in all? Therefore, the objectives of a human asset division reflect and bolster the objectives of the remainder of the association.

Scientists have also explored some of the specific roles that HR professionals have in organizational change (Mansour, Heath \& Brannan, 2016). There also was some research on human resource competencies. The Human Resource Management Society (2012) assumed the importance of leadership and other skills related to organizational change. Along with these important lines of research, human resource management requires much more knowledge related to this role - both functions and individual specialists, as well as leaders in organizational changes.

Vital human asset the executives is the association between an organizations' HR and its procedures, targets, and objectives. The point of vital human asset the executives are to:

1. Advance flexibility, novelty, and viable benefit.

2. Develop a fit for reason hierarchical culture.

3. Improve business execution.

All together for a vital human asset the executives to be successful, (HR) must assume an essential job as a vital accomplice when organization approaches are made and actualized. Key HR can be shown all through various exercises, for example, recruiting, preparing, and remunerating workers. Vital HR includes taking a gander at ways that HR can have an immediate effect on an organization's development. HR faculty need to receive a key way to deal with creating and holding workers to address the issues of the organization's drawn-out plans. 
HR issues can be a troublesome obstacle to cross for some organizations, there is a wide range of various parts that can confound entrepreneurs and cause them to settle on inadequate choices that hinder the tasks for their workers just as their business. To guarantee that you never need to stress over being lost on HR-related issues again, click the download button underneath for your one-page report of the 7 stages to key human asset the board.

Some studies have examined the impact of human resource management flexibility on company performance. The studies were based on the hypothesis that the flexibility of human resource management promotes innovation in organizations, as well as allow them to more quickly respond to economic changes. The results of Way et al (2015) showed that the components of human resource management flexibility, in particular the flexibility of human resource practice, are closely related to high-performance work practices and have a significant independent impact on the company performance (both positive and negative). (Al-Jabari, M. 2013)

It tends to be presumed that HR can be a wellspring of maintainable upper hand for associations. Experimentally, countless investigations have distinguished a positive connection between organization execution and dynamic, profoundly gifted, and elite work frameworks (Fabling \& Grimes, 2010; Fomina et al., 2019).

Thus, the works mentioned above considered the issue of human resource management, as well as its impact on the activities of organizations. However, it should be noted that they consider the general vision rather than particular cases, for example, the work of non-governmental organizations.

Modern companies pay particular to the integration of human resources planning and organization strategies, which is a revolutionary departure from the old service model. In the organization, the HR manager cooperates with line managers. Their joint efforts contribute to achieving the goals of the enterprise through staff selection.

General Managers have to make important decisions in human resource management considering company characteristics and possible difficulties in human resource management. In order to ensure efficient work with the personnel, it is necessary to take into account various factors (for example, the interests of stakeholders, situational factors, the choice of the human resource management policy, commitment to results, competence, coherence, and economic efficiency), as well as long-term consequences, which include organizational effectiveness, individual and social well-being.

Situational factors and stakeholder interests act as constraints on human resource management policies. At the same time, they may also depend on these policies. The choice of the human resource management policy affects the immediate organizational results in human resources and long-term consequences. Thus, the components of human resource management cannot be considered separately as they affect the successful performance of the company in the aggregate.

The relevance of the research consists of the insufficiently studied correlation between human resource management and the operation of non-governmental organizations. Thus, it will allow us to draw conclusions that can be used to set the development priorities of such organizations, as well as for further studies. The study is also relevant for the world practice as the correlation may exist regardless of the company's location.

\section{LITERATURE REVIEW}

The researchers have been studying the relationship between human resource management and company activities since the early 1990s. Although there is no general consensus on the definition in the literature, there is a widespread agreement that human resource management is "a model for the planned allocation of human resources and activities developed to help a company to achieve its goals" (Wright \& McMahan, 1992). This definition focused on how companies design and coordinate human resource practices to support their strategies.

According to Bodla \& Ningyu (2017), the human resource function, its leaders, and practice play an important role in organizational change. In particular, specific practices can be implemented through the human resource management function; these practices enhance the perception and commitment of employees to change. According to the empirical results of the study by Maheshwari \& Vohra (2016), transformative human resource practices contribute to employee adaptation and contextual factors related to human resource management mitigate the negative relationship between employee resistance to change and their creativity. In addition, in high-tech companies experiencing high turbulence, human resource practices support a competitive advantage by developing networks of top management teams (Hon et al., 2014).

According to Gurbuz \& Bingol (2007), there are three approaches to human resource management:

(1) Universal or advanced;

(2) Adaptive;

(3) Resourceful.

The "universal" and "adaptive" approaches focus on the ability of the HR manager to create the prerequisites for better organizational outcomes. On the other hand, the "resourceful" approach provides a conceptual and theoretical rationale 
for human resource management. The early studies on the relationship between efficiency and improving organizational structure suggested the prevalence of the best practice, which emphasized the stability of human resource management practices in organizations.

According to Akhtar, Ding \& Ge (2008), this methodology proposes that some human asset exercises are superior to other people; along these lines, associations need to decide and embrace the ones that are the most appropriate for them. At the end of the day, when associations receive best practices, their exhibition is improved. These practices incorporate inner vocation openings (interior recruiting), formal preparing frameworks (sufficient preparing open doors for their representatives to create vital abilities), result-driven assessments (execution based appraisals), professional stability (work certainty), cooperation (association in critical thinking and dynamic) and benefits assignment (thinking about generally speaking execution on an economical premise) (Colbert, 2004).

Various examinations show that few HRM rehearses at little and medium ventures are impacted by authoritative logical factors including proprietorship, age, and size of firms (Zheng and Morrison, 2009), despite the fact that the degree of the convention of HR rehearses at these organizations is low (Kotey and Slade, 2007). Utilizing information from smaller scale, little, and medium firms in Australia prompts the way that human asset rehearses increment with expanding firm size (Kotey and Slade, 2007). There are two key reasons why this exploration may hope to locate a positive connection between firm size and formalization of HRM rehearses: First, if associations become bigger, the need to decentralize and convey among workers and divisions increments. This, thus, requires a specific degree of normalization, specialization and formalization of HRM (Nooteboom, 1993). Second, most formalized HRM requires extensive improvement costs (Klaas et al., 2000). This outcome in a cost advantage for bigger firms, which is fortified by the restricted stock of money related assets of numerous little firms. While most investigations demonstrate that association size affects HR rehearses (De Kok and Uhlaner, 2003; Kotey and Slade, 2007; Mayson and Barrett, 2005; Mazzarol, 2003; Wiesner and McDonald, 2001), different examinations show that hierarchical size limitedly affects HR works on (Ding and Akhtar, 2006).

At the Palestinian level, the economy has been confronted with overpowering difficulties since September 2000. It has been managing a tight conclusion arrangement, geological fracture, a detachment boundary that essentially decreases agrarian land, unsure open income and contributor help, dissolved beneficial limit, a variety of giver plans, and constrained government and institutional limit. The conclusion takes care of an endless loop whereby the subsequent misfortune in pay obliges yield from the interesting side, while vulnerability and the greater expense of imported sources of info, transportation and capacity compel yield from the stock side. Israel's conclusion arrangement is generally perceived as one of the most wrecking factors constraining the Palestinian economy (PNA, 2008). Subsequently, little is known about human asset the executive's forms inside the Palestinian regions and how modernization has molded, and is a molding, the board methods of reasoning and rehearses, and the objective of this investigation is to make a superior comprehension of the variables influencing HR rehearses in broadened Palestinian associations.

\section{METHODS AND MATERIALS}

The study was conducted in order to collect information to track the possible correlation between the activities of nongovernmental organizations and human resource management. The major tasks of the research were the collection of statistical data and their subsequent interpretation. Based on the study results, we defined the problem and developed possible solutions. To accomplish the targets of the investigation, a review among the administration and workers of six non-legislative associations working in different fields (instructive, sports, beneficent, logical) was directed. An aggregate of 150 individuals was met. The Pearson chi-squared test was utilized to compute starter approaches which are as of late utilizing and last discoveries.

In addition, the study can be used as the basis for further in-depth research, which may also be focused on business corporations, as well as government agencies.

Thus, we can distinguish the following research objectives:

- To sample non-governmental organizations working in various fields in order to expand the scope of the study;

- To conduct a survey among the employees of these organizations to track the possible correlation between the activities of non-governmental organizations and human resource management;

- To analyze the survey results and define the possible problem(s) in this area;

- To suggest possible solutions to the problem (develop recommendations).

We used a quantitative research method in order to collect statistical data. After collecting the necessary information, the analysis of the survey results was performed in the STATISTICA system using the Pearson chi-square criterion. The software allows visualization of data in the statistical analysis.

Before conducting the study, it was necessary to identify the organizations that were ready to take part in it. The first step was to review all non-governmental organizations registered on the website of the Ministry of Justice of the Russian 
Federation (http://unro.minjust.ru/). After selecting the organizations, we sent them emails inviting them to participate in the study. Hence, six organizations were approved.

Table 1: Organizations that took part in the survey

\begin{tabular}{cll}
\hline No. & Non-governmental organization & Activities \\
\hline 1. & $\begin{array}{l}\text { Academic scientific and technical center of } \\
\text { the Russian Academy of Architecture and } \\
\text { Construction Sciences }\end{array}$ & $\begin{array}{l}\text { Scientific and technical support for the restoration of } \\
\text { complex and unique objects }\end{array}$ \\
\hline 2. & $\begin{array}{l}\text { The Wonderworker Seraphim of Sarov } \\
\text { Charity Fund }\end{array}$ & Charity \\
\hline 3. & $\begin{array}{l}\text { Certification center of explosion-proof and } \\
\text { mine electrical equipment }\end{array}$ & $\begin{array}{l}\text { Assessment of the compliance of equipment to the } \\
\text { standards; registration of documents provided there is } \\
\text { a positive result. }\end{array}$ \\
\hline 4. & $\begin{array}{l}\text { "Bulldog and Bear" foreign language } \\
\text { school }\end{array}$ & Delivery of learning services \\
\hline 5. & Youth sports supporting fund & Support for the healthy development of children \\
\hline 6. & All-Russian Sambo Federation & Sports
\end{tabular}

Table 1 shows that the organizations selected for the study carry on different business activities: educational, sports, charitable, scientific.

The study is based on a two-stage survey. A total of 150 people were interviewed: 30 managers and 120 employees of the selected organizations. All employees were asked to fill in electronic forms. They were invited to highlight the points that could be applied to their organization.

The first stage of the survey was quite general and contained questions aimed at identifying the activity model of the company. At this stage, it was important to find out whether the personnel policy of the company corresponds to its development priorities, as well as the degree of employee involvement in activities. Top management was involved in this stage of the survey.

The next stage of the survey was more personal and was aimed at determining the level of employee satisfaction. This stage is extremely important as the more employees are satisfied with the organization; the greater efficiency can be expected from their activities. In addition, the level of satisfaction is also formed through a competent personnel policy that contributes to the creation of a cohesive team. This stage of the survey involved company employees.

\section{RESULTS}

As it has already been mentioned, the Pearson chi-square method was used to analyze the data. It allowed us to conclude that there is a statistical relationship between human resource management and the operation of non-governmental organizations.

Before the data analysis based on the Pearson chi-squared test, we analyzed the questionnaires completed by managers and employees. Two criteria for the chi-squared analysis were selected: "satisfied" and "dissatisfied". The method requires a certain form of data entry. The questionnaire was classified as "satisfied" if it contained more than $70 \%$ of "yes" answers. Thus, there were 25 manager questionnaires and 94 employee questionnaire in the "satisfied" category. The "dissatisfied" category included 5 manager questionnaires and 26 employee questionnaires.

Based on the answers of the management, it is possible to draw a preliminary conclusion that the development priority of the interviewed organizations is somehow related to personnel policy: most respondents agreed that personnel strategies are effectively integrated with the organization strategy. They also noted that employees are actively involved in the life of the company.

The preliminary survey results of the employees demonstrate that they are satisfied with their organization's policies. However, at the moment it is impossible to conclude whether this is statistically related to human resource management.

Next, the statistical significance of the correlation between human resource management and the operation of the organization was determined:

Table 2: Statistical significance of the correlation between human resource management and the operation of the organization

\begin{tabular}{llll}
\hline & Satisfied & Dissatisfied & Total \\
\hline Managers & 25 & 5 & 30 \\
\hline Employees & 94 & 26 & 120 \\
\hline Total & 119 & 31 & 150 \\
\hline
\end{tabular}


Next, the expected value was calculated for each box:

Table 3: Expected values

\begin{tabular}{llll}
\hline & Satisfied & Dissatisfied & Total \\
\hline Management & $30 * 119 / 150=23,8$ & $30 * 31 / 150=6,2$ & 30 \\
\hline Employees & $120 * 119 / 150=95,2$ & $31 * 120 / 150=24,8$ & 120 \\
\hline Total & 119 & 31 & 150 \\
\hline
\end{tabular}

We calculated the Pearson chi-squared criterion and the significance level: 0.366 and 0.546 , respectively.

In order to determine whether there is a statistical correlation between human resource management and the operation of non-governmental organizations, it is necessary to compare these two indicators. If the significance level exceeds the chi-square criterion, there is no statistical relationship between these phenomena.

The significance level exceeds the chi-squared criterion by $0.18: 0.546>0.366$. Thus, it can be concluded that there is no statistically important relationship between human resource management and the operation of non-governmental organizations.

However, it should be noted that these results are quantitative. Therefore, there is a possibility of a more in-depth study. In addition, the preliminary results (response categorization for calculating the chi-squared criterion) make it possible to assume the relationship between human resource management and the operation of the company. Most managers noted the relationship between personnel strategies and organization strategies, as well as the importance of human resource development. The employees emphasized a favorable working environment and warm relations with colleagues. According to $83 \%$ of the employees, personnel policies in organizations are competent.

Human resource management is a component of company activities that can have a positive and negative impact on company performance.

China's rapid economic growth has significantly increased its need for creativity and created fierce competition between companies. The sampling used in this study includes creativity-oriented companies. The organizations operate in the production, technical, and energy sectors in the Chinese provinces of Hubei, Guangdong, and Sichuan. Each of these creativity-oriented companies has research and development teams (Hong et al., 2018).

Thus, the main difference between this study and ours is that it examines the activities of commercial organizations. It is also focused on the narrower aspect of human resource management - its impact on the creative approach in the company.

The questionnaire was originally compiled in English. The inverse translation method was used to ensure that measures in the Chinese version were equivalent to those in the original one. The participants were asked to assess the extent to which they agree with what is described in each paragraph on the topic of teamwork. All variables were measured on a seven-point Likert scale ( $1=$ strongly disagree; $7=$ strongly agree) (Piening et al., 2014).

The authors of the study developed a theoretically substantiated and empirically validated tool for measuring human resource management in the Chinese context based on previous studies and on-site survey results. It has been found that human resource management includes three aspects (i.e. interpersonal benefits, value inheritance, and collective corporate law) that determine employee attitudes and behavior towards teamwork benefits (Liu et al., 2017).

The study also revealed that human resource management has a direct impact on radical creativity rather than incremental. Radical creativity requires newer and more constructive ideas to create breakthroughs (Gilson et al., 2012). Collaboration and trusting relationships can increase the efficiency of knowledge sharing and transmission (Messersmith et al., 2011). Accordingly, competent human resource management can improve the digestion of tasks and perseverance within a team, as well as encourage research, spontaneity and interest in the working environment. Moreover, it has an indirect impact on both radical and incremental creativity, which indicates the different roles of interpersonal harmony in terms of creativity and team (Russo et al., 2018).

Thus, the authors of the study obtained nearly the same results as we did in our study: there is a correlation between the working environment created by talent acquisition and company performance. However, a narrower criterion is considered there.

The study involved six Russian non-governmental government organizations operating in various spheres, among which organization of human rights activities, the purpose of which is to protect human rights, freedoms, and legitimate interests. To achieve the objectives of the study, we conducted a survey of the managers and employees of the selected organizations. The Pearson chi-squared method was used to analyze the results. Both preliminary and final data were considered.

The preliminary analysis of the questionnaires showed that a competent personnel policy can have a positive impact on the activities of organizations by hiring qualified employees, as well as creating a favorable working environment that contributes to motivation. However, according to the analysis of the Pearson chi-squared criterion, there is no 
statistically important relationship between human resource management and the operation of non-governmental organizations. This may be explained by the fact that there are other significant factors affecting the operation of the company and being involved in the human resource management policy. That is why it is important to consider each factor in combination with the others.

The data allow us to conclude that human resource management in the considered non- governmental organizations affect their functioning. However, despite this, there may be other significant factors (for example, economic, technological, psychological, etc.) affecting company performance and involved in human resource management policies. In view of this, the effect of any factor on company activities should be considered based on its combination with other factors. However, it is true that a competent personnel policy contributes to successful company development. Thus, organizations should have clear requirements for their employees. This will allow them to hire employees in accordance with their company criteria. In addition, it is necessary to create a favorable working environment, which can also positively affect company performance. In general, despite the fact that there is no statistically significant correlation between human resource management and the activities of non-governmental organizations, this criterion cannot be excluded from development priority planning.

\section{CONCLUSION}

Organizations are bound to be effective when all groups are progressing in the direction of similar goals. Vital HR does the examination of representatives and decides the activities required to expand their incentive to the organization. Key human assets the board likewise utilizes the consequences of this examination to create HR strategies to address representative shortcomings.

However, a competent personnel policy is one of the components of the successful development of the company. Therefore, organizations should have clear requirements for their employees in order to hire them in accordance with the company criteria. In addition, it is necessary to create a favorable working environment, which can also positively affect company performance by increasing the motivation of employees. In general, despite the fact that there is no statistically significant correlation between human resource management and the activities of non-governmental organizations, this criterion cannot be excluded from development priority planning.

Further research may involve other organizations (including commercial companies) and be conducted in other countries. In addition, it is possible to study the impact of the relationship of personnel policy with other factors of the organization. The practical value of our research is the possibility to better consider the correlation between human resource management and the activities of non-governmental organizations.

\section{LIMITATION AND STUDY FORWARD}

This study was conducted on the management and staff of only six NGOs active in various fields, which can also be considered for government agencies.

\section{ACKNOWLEDGMENT}

The author confirms that the data do not contain any conflict of interest.

\section{REFERENCES}

1. Akhtar, S., Ding, D. Z., \& Ge, G. L. (2008). Strategic HRM practices and their impact on company performance in Chinese enterprises. Human Resource Management: Published in Cooperation with the School of Business Administration, The University of Michigan and in alliance with the Society of Human Resources Management, 47(1), 15-32. https://doi.org/10.1002/hrm.20195

2. Bodla, A. A., \& Ningyu, T. (2017). Transformative HR practices and employee task performance in high-tech firms. Journal of Organizational Change Management. https://doi.org/10.1108/JOCM-02-2016-0030

3. Colbert, B. A. (2004). The complex resource-based view: Implications for theory and practice in strategic human resource management. Academy of management review, 29(3), 341-358. https://doi.org/10.5465/amr.2004.13670987

4. Fabling, R., \& Grimes, A. (2010). HR practices and New Zealand firm performance: What matters and who does it?. The International Journal of Human Resource Management,21(4), 488-508. https://doi.org/10.1080/09585191003611994

5. Fomina, S., Sizikova, V., Shimanovskaya, Y., Kozlovskaya, S., \& Karpunina, A. (2019). The effect of teaching and supply chain management on employees' skills in small and medium sized enterprises of Russia. International Journal of Supply Chain Management, 8(4), 930-938.

6. Gilson, L. L., Lim, H. S., D'Innocenzo, L., \& Moye, N. (2012). One size does not fit all: Managing radical and incremental creativity. The Journal of Creative Behavior, 46(3), 168-191. https://doi.org/10.1002/jocb.12

7. Gurbuz, S., \& Bingol, D. (2007). Cesitli orgut yoneticilerinin guc mesafesi, belirsizlikten kacınma, eril-disil ve bireyci-toplulukcu kultur boyutlarına yonelik egilimleri uzerine gorgul bir arastirma. KHO Savunma Bilimleri Dergisi, 6(2), 68-87. 
8. Hon, A. H., Bloom, M., \& Crant, J. M. (2014). Overcoming resistance to change and enhancing creative performance. Journal of Management, 40(3), 919-941. https://doi.org/10.1177/0149206311415418

9. Hong, J., Hou, B., Zhu, K., \& Marinova, D. (2018). Exploratory innovation, exploitative innovation and employee creativity. Chinese Management Studies. https://doi.org/10.1108/CMS-11-2016-0228

10. Liu, D., Gong, Y., Zhou, J., \& Huang, J. C. (2017). Human resource systems, employee creativity, and firm innovation: The moderating role of firm ownership. Academy of Management Journal, 60(3), 1164-1188. https://doi.org/10.5465/amj.2015.0230

11. Maheshwari, S., \& Vohra, V. (2015). Identifying critical HR practices impacting employee perception and commitment during organizational change. Journal of Organizational Change Management. https://doi.org/10.1108/JOCM-03-2014-0066

12. Mansour, H. F., Heath, G., \& Brannan, M. J. (2016). Exploring the role of HR practitioners in pursuit of organizational effectiveness in higher education institutions. Journal of Change Management, 15(3), 210-230. https://doi.org/10.1080/14697017.2015.1045539

13. Messersmith, J. G., Patel, P. C., Lepak, D. P., \& Gould-Williams, J. S. (2011). Unlocking the black box: Exploring the link between high-performance work systems and performance. Journal of Applied Psychology, 96(6), 1105-1118. https://doi.org/10.1037/a0024710

14. Piening, E. P., Baluch, A. M., \& Ridder, H. G. (2014). Mind the intended- implemented gap: Understanding employees' perceptions of HRM. Human Resource Management, 53(4), 545-567. https://doi.org/10.1002/hrm.21605

15. Russo, S. D., Mascia, D., \& Morandi, F. (2018). Individual perceptions of HR practices, HRM strength and appropriateness of care: A meso, multilevel approach. The International Journal of Human Resource Management, 29(2), 286-310. https://doi.org/10.1080/09585192.2016.1165276

16. Way, S. A., Tracey, J. B., Fay, C. H., Wright, P. M., Snell, S. A., Chang, S., \& Gong, Y. (2015). Validation of a multidimensional HR flexibility measure. Journal of Management, 41(4), 1098-1131. https://doi.org/10.1177/0149206312463940

17. Wright, P. M., \& McMahan, G. C. (1992). Theoretical perspectives for strategic human resource management. Journal of management, 18(2), 295-320. https://doi.org/10.1177/014920639201800205

18. Al-Jabari, M. (2013). Factors affecting human resource practices in a sample of diversified Palestinian organizations. Tourism \& Management Studies, 594-603.

19. Zheng, C., O'Neill, G., \& Morrison, M. (2009). Enhancing Chinese SME performance through innovative HR practices. Personnel Review. https://doi.org/10.1108/00483480910931334

20. Kotey, B., \& Slade, P. (2005). Formal human resource management practices in small growing firms. Journal of small business management, 43(1), 16-40. https://doi.org/10.1111/j.1540-627X.2004.00123.X

21. Nooteboom, B. (1993). Firm size effects on transaction costs. Small business economics, 5(4), $283-295$. https://doi.org/10.1007/BF01516249

22. Klaas, B. S., McClendon, J., \& Gainey, T. W. (2000). Managing HR in the small and medium enterprise: The impact of professional employer organizations. Entrepreneurship Theory and Practice, 25(1), 107-124. https://doi.org/10.1177/104225870002500109

23. De Kok, J., Uhlaner, L. M., \& Thurik, R. (2003). Human resource management with small firms; facts and explanations.

24. Mayson, S. E., \& Barrett, R. J. (2006). Human resource management in small firms: evidence from growing small firms in Australia. In Human resource strategies for the high growth entrepreneurial firm (pp. 223-243). Information Age Publishing.

25. Mazzarol, T. (2003). A model of small business HR growth management. International Journal of Entrepreneurial Behavior \& Research. https://doi.org/10.1108/13552550310461036

26. Wiesner, R., \& McDonald, J. (2001). Bleak house or bright prospect? Human resource management in Australian SMEs. Asia Pacific Journal of Human Resources, 39(2), 31-53. https://doi.org/10.1177/103841110103900203

27. Authority, P. (2008). Palestinian Reform and Development Plan 2008-2010. Palestinian Authority.

28. Ding, D. Z., Akhtar, S., \& Ge, G. L. (2006). Organizational differences in managerial compensation and benefits in Chinese firms. The international journal of human resource management, 17(4), 693-715. https://doi.org/10.1080/09585190600581675

Questionnaire Sample

Table 4: Manager Questionnaire

\begin{tabular}{l}
\hline Question \\
\hline $\begin{array}{l}\text { 1. Personnel strategies are effectively integrated with the organization's } \\
\text { strategy. }\end{array}$ \\
\hline 2. The performance analysis considers future development of the company. \\
3. Human resource management is considered as a positive contribution to the \\
development of the organization.
\end{tabular}


4. Company employees are involved in improving company performance and solving problems.

5. Managers encourage the development of skills of their subordinates.

6. Company employees are involved in decision making.

7. The company effectively hires skilled workers.

8. Great attention is paid to teamwork and cooperation.

Table 5: Employee Questionnaire

\begin{tabular}{l}
\hline Question \\
\hline 1. My manager supports me. \\
\hline 2. I have warm relations with my colleagues. \\
\hline 3. My work contributes to my personal growth and development. \\
\hline 4. I am pleased with my work. \\
\hline 5. My work is my hobby. \\
\hline 6. I get a fair salary. \\
\hline 7. I am comfortable with my current workload. \\
\hline 8. I can say that my management and team have common goals. \\
\hline 9. The working environment is always favorable. \\
\hline 10. I believe that there is a competent recruitment policy in my company.
\end{tabular}

